\title{
A Synthetic Study of the Position Difference of the Southern Branch Trough of the Qinghai-Tibet Plateau Based on Objective Identification
}

\author{
Ke $\mathrm{Li}^{1}{ }^{*}$, Shunwu Zhou${ }^{1}$, Xia Shi' ${ }^{1}$, Siyuan Chen ${ }^{2}$, Qianqian Song ${ }^{3}$ \\ ${ }^{1}$ Key Laboratory of Meteorological Disaster of Ministry of Education, Collaborative Innovation Center on Forecast and Evaluation \\ of Meteorological Disasters, Nanjing University of Information Science and Technology, Nanjing, China \\ ${ }^{2}$ State Key Laboratory of Severe Weather, Chinese Academy of Meteorological Sciences, Beijing, China \\ ${ }^{3}$ Shangqiu Meteorological Bureau, Shangqiu, China \\ Email: ^530526460@qq.com
}

How to cite this paper: Li, K., Zhou, S. W., Shi, X., Chen, S. Y., \& Song, Q. Q. (2021). A Synthetic Study of the Position Difference of the Southern Branch Trough of the Qinghai-Tibet Plateau Based on Objective Identification. Journal of Geoscience and Environment Protection, 9, 182-194.

https://doi.org/10.4236/gep.2021.93011

Received: February 28, 2021

Accepted: March 27, 2021

Published: March 30, 2021

Copyright $\odot 2021$ by author(s) and Scientific Research Publishing Inc. This work is licensed under the Creative Commons Attribution International License (CC BY 4.0).

http://creativecommons.org/licenses/by/4.0/

(c) (i) Open Access

\begin{abstract}
The southern branch trough (SBT) mainly appears in the winter half year (November to May of the following year), using the 4 times daily NCEP/NCAR reanalysis data nearly 41 years (1979-2019) to analyze the differences of the SBT distribution of spatial location, frequency in winter and spring, then selects the "eastern type" and "western type" of the 10 most typical SBT, using simplified vertical vorticity tendency equation, using simplified vertical vorticity tendency equation to diagnosis of the SBT in power, heat, water vapor and wave energy in different positions. The results show that: 1) The location of the SBT is more eastward in winter, and more westward in spring. 2) The diagnosis results of the vorticity equation show that the vorticity of the southern branch of the "western type" is mainly contributed by advection term; the vorticity of the "eastern type" south branch is mainly contributed by the non-adiabatic heating term. 3) The SBT of the "eastern type" has more obvious vorticity advection than the southern branch of the "western type", and the dynamic action is stronger. The "western type" SBT has stronger $Q_{1}$, specific humidity advection and water vapor flux than the "eastern type" SBT, which is greatly affected by thermal action and water vapor. When the "eastern type" and "western type" SBT occur, the T-N wave activity flux appears obvious abnormal energy fluctuation propagation.
\end{abstract}

\section{Keywords}

The SBT, Winter, Spring, Full-Type Vertical Vorticity Inclination Equation, 
Dynamic Characteristics, Thermodynamic Characteristics, T-N Wave Activity Flux

\section{Introduction}

The southern branch trough (SBT) is also known as the subtropical southern branch westerly trough (Indo Burma trough), which is a semi-permanent low pressure trough generated by the SBT westerly on the south side of the Plateau during the winter half year (October to May) due to the influence of the large topography of the Plateau (Ye, 1979; Suo \& Ding, 2009; Lin, 2016), is also one of the major weather systems affecting South Asia and East Asia in the winter half year (He et al., 2007; Zhang et al., 2017).

Research in the 1950s showed that the formation and evolution of the SBT were not only influenced by the fluctuation of the upstream westerly wind (Chaudhury, 1950; Tao, 1953), and were closely related to the dynamic and thermal effects of the plateau (Yin, 1949; Yeh, 1950; Bolin, 1950). In the past twenty years, scholars at home and abroad have done a lot of research on the generation, extinction and structure of the SBT. As the most typical winter circulation pattern, the westerly wind is stronger in the late winter, and the Plateau atmosphere is the cold source (Wu et al., 2004; Li, 2016). The atmospheric circulation pattern in late spring is in the transition period from winter to summer, and the cyclonic flow field triggered by sensible heat heating over the Indian Peninsula and latent heat heating over Indo-China Peninsula overlaps each other in the Bay of Bengal, which is conducive to the vortex activity and the formation of low trough in the Bay of Bengal (Qin et al., 1997; Wu, 2010). Suo (2008) discussed the structure, evolution and propagation characteristics of the SBT from the perspective of climatology, and pointed out that the establishment of the SBT indicated that the atmospheric circulation in the Northern Hemisphere changed from summer type to winter type, and the disappearance of the SBT and its transformation into Bay of Bengal Trough was an important symbol of the outbreak of South Asian monsoon. Lin (2015) used objective identification results to find that the generation and depletion development position of the SBT are inseparable from quasi-steady activities and the dynamic and thermal effects of the plateau.

There are significant differences in the genesis, structure and thermal properties of the Indo-Burma trough in winter and summer (Chen et al., 2006). Suo (2008) believed that the steady Rossby wave energy from North Africa propagated to the Bay of Bengal along the jet guide might be another main mechanism for the obvious increase of the SBT. This article uses 4 times daily NCEP/NCAR reanalysis data nearly 41 a (1979-2019) objectively to identify the SBT, analyzes the spatial distribution of winter and spring in the SBT, frequency characteristics, it is divided into "western type" southern trough and "eastern type" southern trough, and selects the top 10 strongest SBT of each model as a typical example, compare the SBT in the power field, thermal field and energy differences, 
analysis of southern trough may cause in different locations, to deepen the cognition to the southern trough.

\section{Data and Methods}

\subsection{Data}

The main materials used in this paper include:

1) NCEP/NCAR data were reanalyzed for 41 years from January 1, 1979 to December 31,2019 , with a resolution of $2.5^{\circ} \times 2.5^{\circ}$, including horizontal zonal wind, meridional wind, temperature, specific humidity, geopotential height, vertical velocity and relative humidity.

2) in October 1996-October 2015 Global Precipitation Climatology Project (GPCP) daily rainfall data, a resolution of $1^{\circ} \times 1^{\circ}$, the Precipitation data comprehensive scores of stationary satellite and polar orbit satellite infrared and microwave data and after Global multiple stations data correction of satellite rainfall products, this article USES the latest version 4 (Adler et al, 2018).

\subsection{Main Methods}

\subsubsection{Objective Identification Method of SBT}

The south branch is generally the short wave trough on the guide branch westerly flow, which is most active in the middle and lower troposphere $(850 \mathrm{hPa}$ $500 \mathrm{hPa}$ ). Considering that Southwest China is affected by the altitude topography of Qinghai-Tibet Plateau and Yunnan-Guizhou Plateau and that $500 \mathrm{hPa}$ has the greatest impact on the plateau, $500 \mathrm{hPa}$ is paid more attention to in synoptic area (Lin, 2015), so this paper chooses $500 \mathrm{hPa}$ height field for analysis.

The reanalysis data used for objective identification has a higher spatial resolution and can identify the midpoint of the shear line more accurately than the manual method, which can greatly reduce the arbitrariness (human nature) of determining the midpoint of the SBT.

Based on the discrimination method of low pressure trough proposed by Herrera et al. (2001), and the objective identification method of the south support trough by Lin (2015), a new analysis grid was constructed with NCEP/NCAR grid points along the midpoint on the latitude line. $3 \times 4$ grid points around the analysis grid points were taken to calculate the height value $\mathrm{HZ}_{1}$ in the square. Take the $3 \times 5$ grid point boxes $Z_{2}$ and $Z_{3}$ on the east and west sides of $Z_{1}$ to calculate their average height values $\mathrm{HZ}_{2}$ and $\mathrm{HZ}_{3}$. The height difference between the average value of $\mathrm{HZ}_{2}$ and $\mathrm{HZ}_{3}$ and $\mathrm{HZ}_{1}$ is $\mathrm{DH}$, and the grid point with $\mathrm{DH}<$ 2.5 dagpm is called slot area. Starting from the maximum $\mathrm{DH}$ point $\left(\mathrm{P}_{0}\right)$ in each groove area, scan the maximum $\mathrm{DH}$ point $\left(\mathrm{P}_{1}\right)$ with a distance of no more than 1.5 grids (about $\times$ grid distance) on the upper and lower latitude lines adjacent to $\mathrm{P}_{0}$, and cycle the previous process from $\mathrm{P}_{1}$ until no new groove points can be found. All the connections of groove points are groove lines.

\subsubsection{Diagnostic Method of Full-Type Vorticity Vertical Dip Equation}

Using atmospheric dynamic and thermodynamic equations of thermodynamic 
and dynamic variables, the deformation process of atmospheric motion equation combined with thermodynamic equation, $\mathrm{Wu}$ and Liu (1999) is derived explicitly includes thermal and dynamic effects of the type of vorticity equation, and study the position of the western Pacific subtropical high may cause abnormal. Guan et al. (2010) analyzed the relationship between plum rains and the Western Pacific subtropical high based on this equation. Zhang et al. (2019) used this equation to explore the relationship between plateau shear line and plateau non-adiabatic heating.

The full-type vertical vorticity inclination equation can be written as $(\mathrm{Wu} \&$ Liu, 1999):

$$
\begin{aligned}
& \frac{\partial \zeta}{\partial t}+V \cdot \nabla \zeta+\beta v \\
& =(1-\kappa)(f+\zeta) \frac{\omega}{P}-(f+\zeta) \frac{Q}{\theta}+\frac{1}{\alpha} \frac{\mathrm{d}}{\mathrm{d} t}\left[\frac{P_{E}}{\theta_{z}}-C D\right] \\
& \quad+\frac{1}{\theta_{z}} F_{\zeta} \cdot \nabla \theta_{z}+\frac{f+\zeta}{\theta_{z}} \frac{\partial Q}{\partial z}-\frac{1}{\theta_{z}} \frac{\partial v}{\partial z} \frac{\partial Q}{\partial x}+\frac{1}{\theta} \frac{\partial u}{\partial z} \frac{\partial Q}{\partial y}, \quad \theta_{z} \neq 0
\end{aligned}
$$

When the change of thermal structure inside the atmosphere, the influence of heat source itself and friction dissipation are not taken into account, and only the effect of external heat source is considered, Equation (1) can be simplified as:

$$
\frac{\partial \zeta}{\partial t}+V \cdot \nabla \zeta+\beta v=(1-\kappa)(f+\zeta) \frac{\omega}{P}+\frac{f+\zeta}{\theta_{z}} \frac{\partial Q}{\partial z}-\frac{1}{\theta_{z}} \frac{\partial v}{\partial z} \frac{\partial Q}{\partial y}
$$

$Q$ at the right end of Equation (2) is the non-adiabatic heating rate in the thermodynamic equation. $\theta_{z}=z$, Other symbols are commonly used in meteorology. Wang et al. (2005) further simplified the above equation as follows:

$$
\frac{\partial \zeta}{\partial t}=-V \cdot \nabla \zeta-\beta v+\frac{f+\zeta}{\theta_{z}} \frac{\partial Q_{1}}{\partial z}
$$

In Equation (3), the heat source is regarded as the atmospheric apparent heat source $Q_{I}$, the right end of the equation is vorticity advection term (referred to as advection term), $\beta$ effect term (referred to as $\beta$ term) and non-adiabatic heating term (denoted as $Q_{I z}$ ).

\section{Spatial Distribution of the SBT in Winter and Spring}

In Feng and Chen (2019) statistics on the activity frequency of the SBT during 1981-2017, the average annual occurrence of the SBT was 46.4 times, while in this paper, it was 48.2 times (18.5 times), which was slightly different, which may be caused by the difference in the statistical time range and statistical area. The spatial distribution of winter and spring season show (Figure 1), nearly 41 a southern trough generating frequency of differences in the spatial distribution forms, including spring (Figure 1(a)) southern trough points, strongest frequency high value center is located in $\left(25^{\circ} \mathrm{N}, 70^{\circ} \mathrm{E}\right)$, near the high value center east range of multiple low don't rule out the possibility of from west to east with the west wind drift at this point. In spring (Figure 1(b)), the south branch 


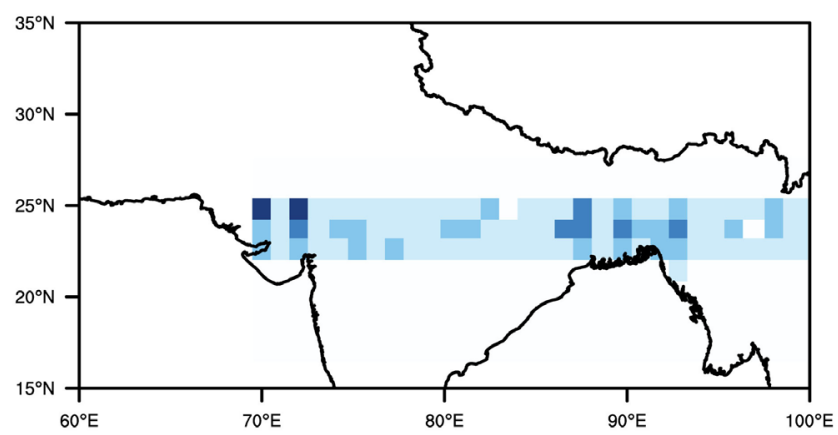

(a)

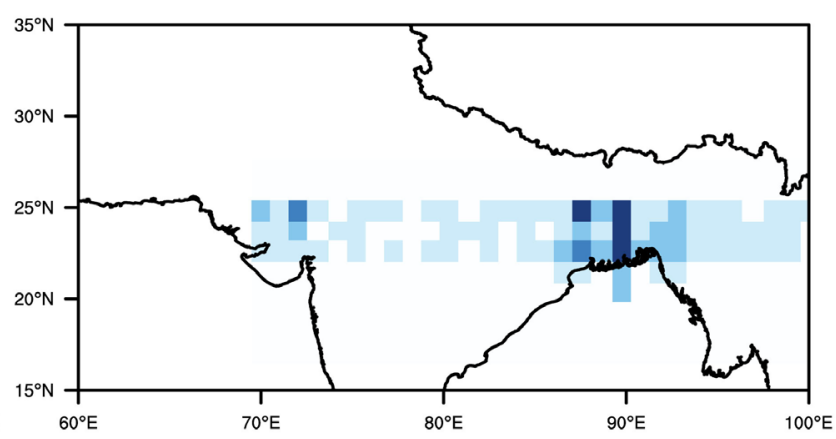

(b)

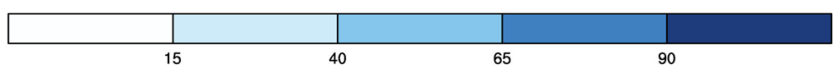

Figure 1. Spatial distribution of the generation frequency (shadow, unit: times) of the SBT in January (a) and May (b) during the past 41 years.

mainly appeared in the vicinity of $\left(24^{\circ} \mathrm{N}, 90^{\circ} \mathrm{E}\right)$. Compared with winter, the spatial distribution of the south branch in spring was obviously eastward, and the distribution area was more concentrated.

January and May are the two peak periods in the SBT. According to the intensity standard, the 10 strongest typical cases in winter and spring during the recent 41 years are selected for analysis respectively. In terms of intensity selection, the top $10 \%$ of intensity was selected. The average intensity of typical cases in the south branch of this month was 9.86 dagpm, which was 3.944 times higher than the identification standard of the south branch (2.5 dagpm). The average strength of the typical cases in the south branch in spring is 5.6 dagpm, which is 2.24 times higher than the identification standard of the south branch (2.5 dagpm). In terms of time selection, it covers three months in winter and spring, and the duration of life history is more than 2 days.

Overall, winter southern trough intensity is stronger than the spring, winter's strongest 10 an average of $70.75^{\circ} \mathrm{E}$ longitude, spring the strongest 10 an average of $85.05^{\circ} \mathrm{E}$ longitude, southern trough in spring than in winter more by east southern trough, so the following winter southern trough as "western type" southern trough, spring southern trough as "eastern type" southern trough for synthetic analysis.

\section{Diagnostic Analysis of Full-Type Vorticity Equation}

In order to more clearly see the causes of the differences in spatial distribution of the SBT, the following analysis is based on the typical cases of the SBT in Table 1 and Table 2. The generation and development of the south branch tank needs a process. In this paper, the maximum time of a typical case of the south branch tank is taken as the 0 time, the maximum time is pushed forward 3 times as the beginning time, and the maximum time is pushed back 3 times as the end time to carry out the statistical synthesis of the time evolution of the diagnostic results of the full-type vorticity equation. 
Table 1. Basic information table of typical cases of the SBT in winter.

\begin{tabular}{ccccc}
\hline Number & Time & Lat, Lon & Strength/dagpm & Frequency/hour \\
\hline $1-1$ & 1980122218 & $70.00^{\circ} \mathrm{E}, 23.75^{\circ} \mathrm{N}$ & 10.45 & 17 \\
$1-2$ & 2002123100 & $72.50^{\circ} \mathrm{E}, 23.70^{\circ} \mathrm{N}$ & 9.48 & 9 \\
$1-3$ & 2013121600 & $80.00^{\circ} \mathrm{E}, 23.70^{\circ} \mathrm{N}$ & 10.08 & 13 \\
$1-4$ & 1995010800 & $72.50^{\circ} \mathrm{E}, 22.50^{\circ} \mathrm{N}$ & 10.50 & 8 \\
$1-5$ & 1999012712 & $70.00^{\circ} \mathrm{E}, 25.00^{\circ} \mathrm{N}$ & 8.90 & 10 \\
$1-6$ & 2015010200 & $73.00^{\circ} \mathrm{E}, 22.50^{\circ} \mathrm{N}$ & 6.70 & 17 \\
$1-7$ & 2017012606 & $75.00^{\circ} \mathrm{E}, 23.75^{\circ} \mathrm{N}$ & 9.10 & 11 \\
$1-8$ & 1994022106 & $73.75^{\circ} \mathrm{E}, 23.75^{\circ} \mathrm{N}$ & 7.12 & 12 \\
$1-9$ & 2003021812 & $70.00^{\circ} \mathrm{E}, 23.75^{\circ} \mathrm{N}$ & 10.71 & 14 \\
$1-10$ & 2019020706 & $70.75^{\circ} \mathrm{E}, 25.00^{\circ} \mathrm{N}$ & 15.56 & 12 \\
Average & & $70.75^{\circ} \mathrm{E}, 23.74^{\circ} \mathrm{N}$ & 9.86 & 12.3 \\
\hline
\end{tabular}

Table 2. Basic information table of typical cases of the SBT in spring.

\begin{tabular}{ccccc}
\hline Number & Time & Lat, Lon & Strength/dagpm & Frequency/hour \\
\hline $5-1$ & 1982030206 & $87.00^{\circ} \mathrm{E}, 23.50^{\circ} \mathrm{N}$ & 8.04 & 20 \\
$5-2$ & 2004031000 & $85.00^{\circ} \mathrm{E}, 22.50^{\circ} \mathrm{N}$ & 7.07 & 14 \\
$5-3$ & 2012031600 & $90.00^{\circ} \mathrm{E}, 23.75^{\circ} \mathrm{N}$ & 6.78 & 16 \\
$5-4$ & 1979040418 & $70.00^{\circ} \mathrm{E}, 25.00^{\circ} \mathrm{N}$ & 6.69 & 12 \\
$5-5$ & 1990040318 & $85.00^{\circ} \mathrm{E}, 23.75^{\circ} \mathrm{N}$ & 6.12 & 23 \\
$5-6$ & 2015041400 & $77.50^{\circ} \mathrm{E}, 22.50^{\circ} \mathrm{N}$ & 4.00 & 16 \\
$5-7$ & 1981052418 & $88.50^{\circ} \mathrm{E}, 25.00^{\circ} \mathrm{N}$ & 4.40 & 10 \\
$5-8$ & 1998051812 & $87.50^{\circ} \mathrm{E}, 20.00^{\circ} \mathrm{N}$ & 4.70 & 12 \\
$5-9$ & 2016052700 & $90.00^{\circ} \mathrm{E}, 22.50^{\circ} \mathrm{N}$ & 4.00 & 15 \\
$5-10$ & 2018050212 & $90.00^{\circ} \mathrm{E}, 22.50^{\circ} \mathrm{N}$ & 4.20 & 18 \\
Average & & $85.05^{\circ} \mathrm{E}, 23.01^{\circ} \mathrm{N}$ & 5.60 & 15.6 \\
\hline
\end{tabular}

Decompose both ends of the equation, and analyze each item at both ends of the equation after decomposition. In this paper, the temporal evolution of the diurnal thermodynamic characteristics of the south branch trough is analyzed from the relationship between the pVor (hereinafter referred to as the local variation of vorticity) and the sum of advection, beta Effect and diabatic $Q_{I}$, (hereinafter referred to as the sum of the three items), as well as the relationship between the sum of the three items and their respective components. As shown in Figure 2(a), the local variation term of January vorticity and the sum of the three terms showed basically the same variation trend in the three stages of the formation, strength and extinction of the south branch trough, and the difference of the average deviation of the two terms was no more than $10 \times 10^{-11} \mathrm{~s}^{-1}$. 


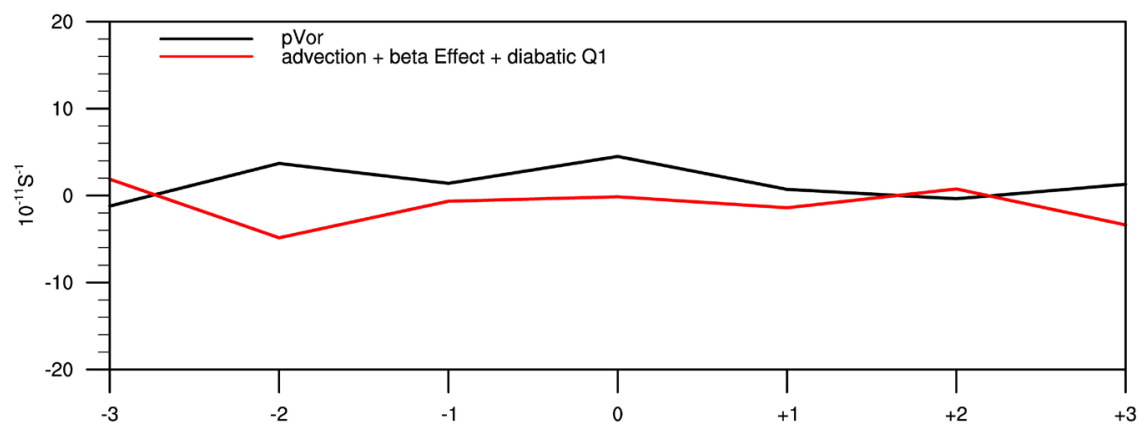

(a)

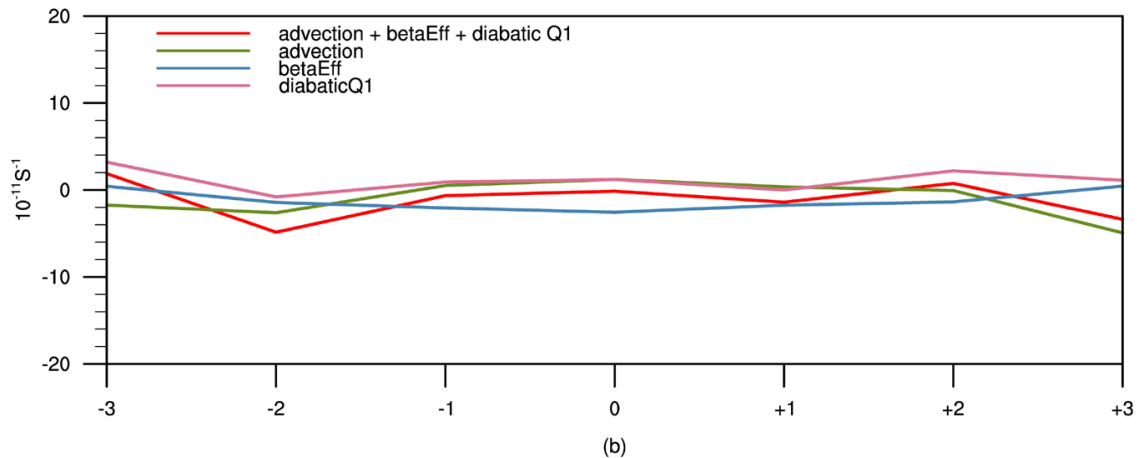

Figure 2. The time evolution of the daily total vorticity equation and its three components in the "western type" SBT. (The abaxial axis is the time series, 0 is the strength of the south branch of the tank, $-1,-2$ and -3 are 6,12 and $18 \mathrm{~h}$ before the strength of the south branch of the tank, respectively, and the rest are the same; The solid black line $\mathrm{pV}$ or is the local change of vorticity, unit: $10^{-10} \mathrm{~s}^{-1}$; The solid green line advection is advection; The solid blue line Beta Effect is the $\beta$-effect term. Diabatic $Q_{1}$ is the non-adiabatic heating term, unit: $10^{-11} \mathrm{~s}^{-1}$ ).

pVor item represents what direction components, $\beta$-effect item on behalf of the north and south direction, $Q_{I}$, from the sum of three and advection item (pVor), paragraphs, beta effect and $Q_{l}$, the decomposition results, west southern trough type as shown in Figure 2(b), the sum of three pVor trend is most consistent with the advection, paragraphs and beta effect and $Q_{I}$ change is not obvious, that southern trough biggest influence pVor item at this time. East southern trough type as shown in Figure 3(b), the sum of the three trends is most consistent with the $Q_{l}$, and paragraphs pVor and beta effect is not obvious change, explain the $Q_{I}$ to the largest contribution to the southern trough, and the $6 \mathrm{~h}$ before the southern trough the strongest moment, namely 1 times, $Q_{I}$ significantly bigger, this may be a local change of vorticity and three combined into one of the important reasons, the deflection at the same time, whether the diabatic heating effect of vorticity has about $6 \mathrm{~h}$ of the indicator in advance. Therefore, the decomposition using the full-type vorticity equation is accurate, that is, it is reasonable and applicable to diagnose the dynamic and thermodynamic changes in January and May.

From the sum of the three terms to advection term, $\beta$-effect term and $Q_{1}$. As shown in Figure 2(b), the sum of the three terms is the most consistent with the 

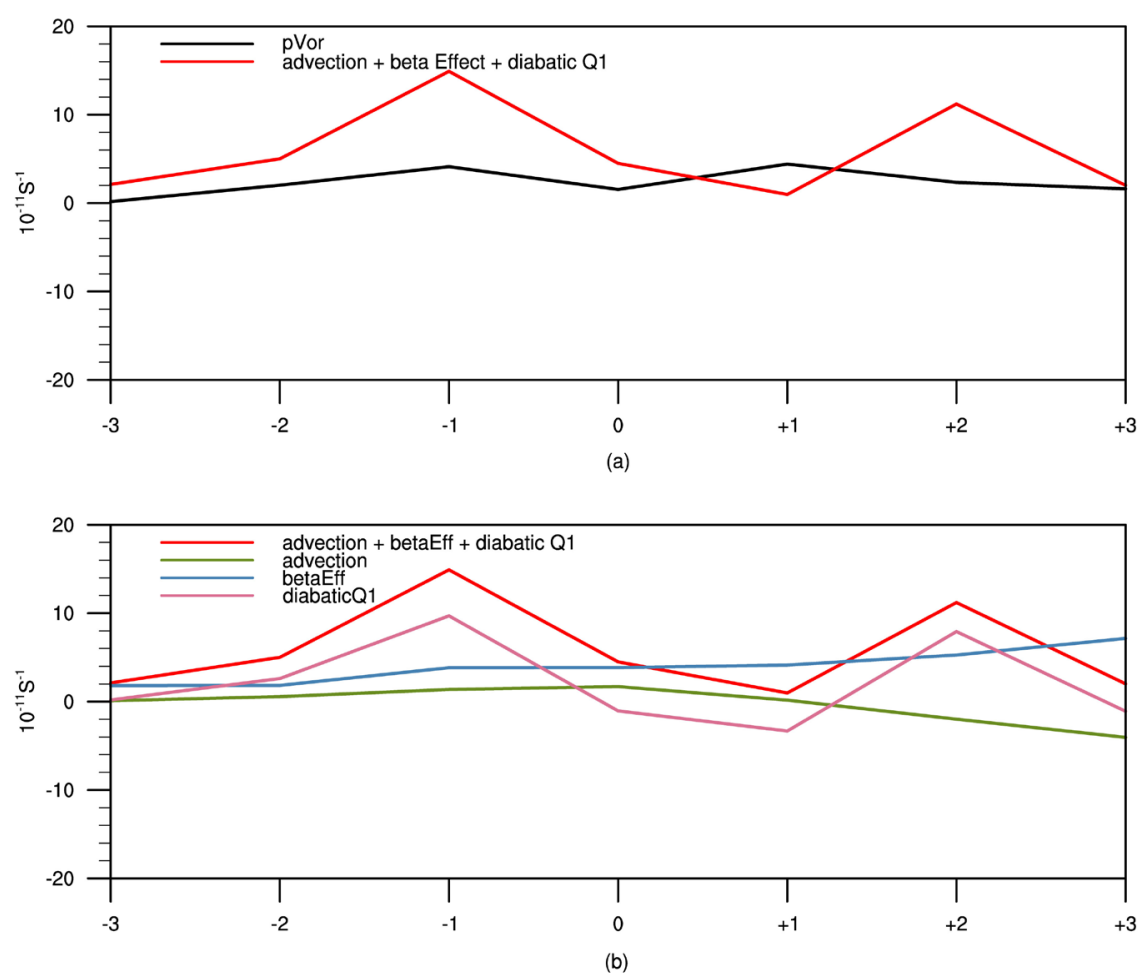

Figure 3. Same as Figure 2, but in the "eastern type" SBT.

variation trend of the horizontal term. The SBT of the eastern type is shown in Figure 3(b), and the sum of the three terms is equal to $Q_{1}$. The variation trend of the term is the most consistent, and $6 \mathrm{~h}$ before the strongest moment of the SBT, $Q_{I}$ may be the most important reason for the larger deviation of the decomposition of the local vorticity change term and the sum of the three terms. Meanwhile, it is also considered whether the non-adiabatic heating has an indicator signal about $6 \mathrm{~h}$ in advance for the vorticity change. This indicates that the decomposition using the full-type vorticity equation is accurate, that is, the diagnosis of the dynamic and thermal changes in January and May is reasonable and applicable.

\section{Difference of SBT at Different Positions}

\subsection{Vorticity Advection and Geopotential Height Field}

The above analysis shows that there are obvious differences in the configuration of dynamic and thermal fields when the SBT appears in winter and spring. Further analysis was made on the relationship between the water vapor flux and vorticity advection (VA) (Figure 4) and specific humidity advection (SHA) of a typical case in the southern branch trough (Figure 5). The positive VA large region of the west type south trough is located near the north of the Indian Peninsula in front of the south trough, and the positive VA large region of the east type south trough is located in the east of the Bay of Bengal. The cyclonic vorticity increases, and the divergence occurs under the action of geostrophic deflection force, thus depressurizing the ground. Moreover, under the action of pressure 


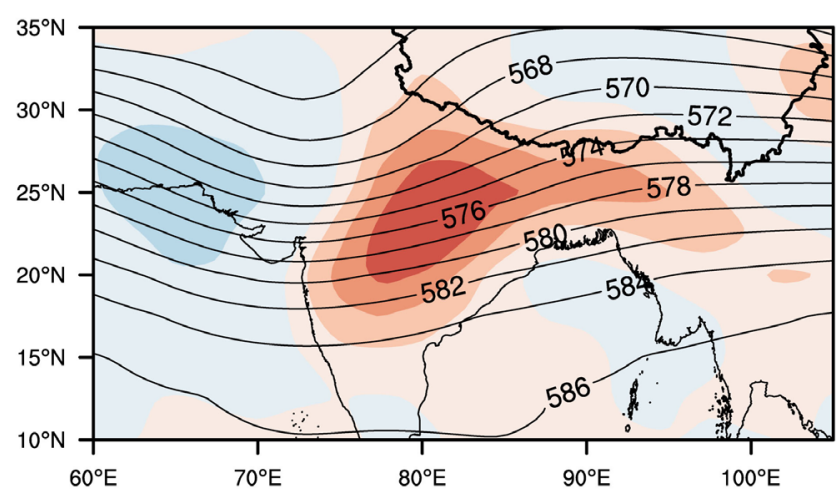

(a)

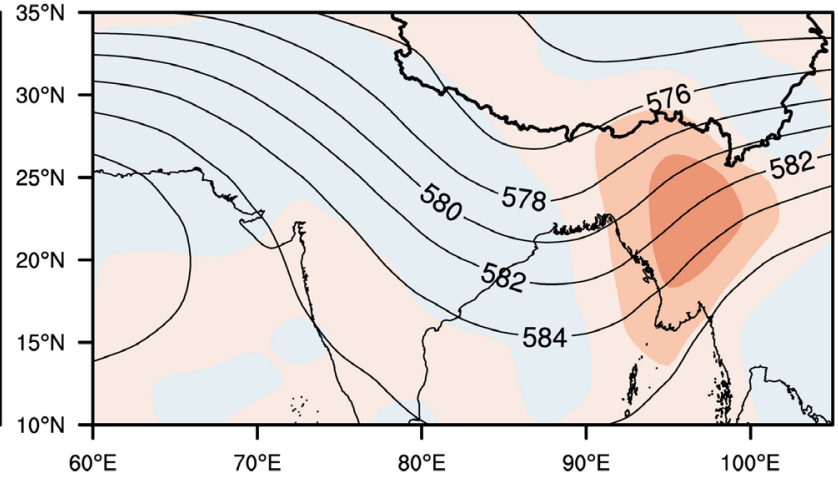

(b)

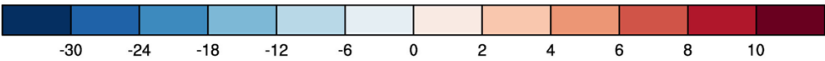

Figure 4. Height fields of $500 \mathrm{hPa}$ for typical cases in the SBT in the "western type" SBT (a) and the "eastern type" SBT (b) (contour lines, unit: dagpm)and VA [Shadow, Unit: $\left.10^{-5} \mathrm{~g} /(\mathrm{kg} \cdot \mathrm{s})\right]$.

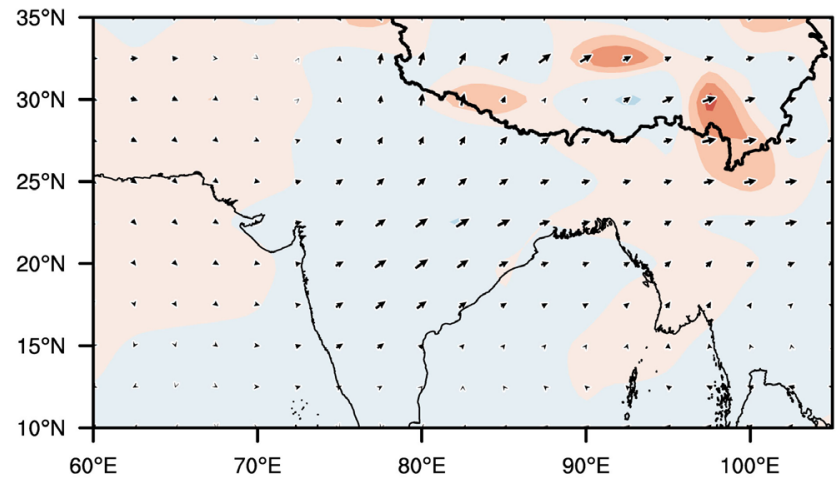

(a)

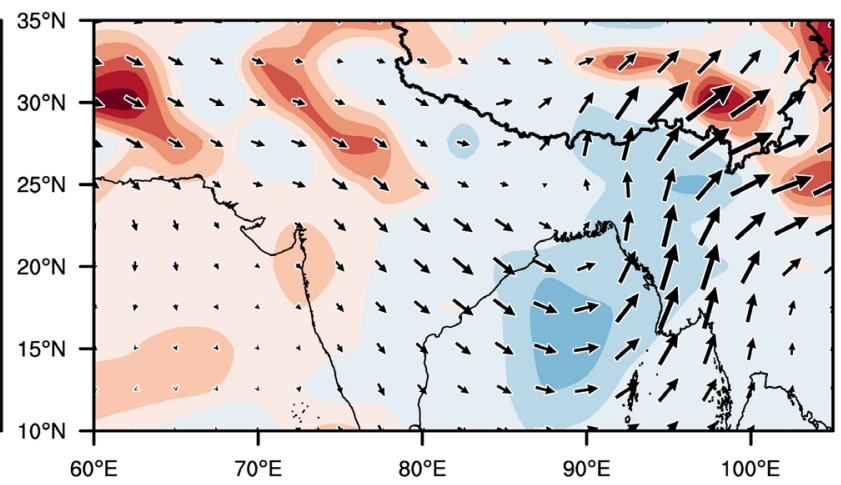

(b)

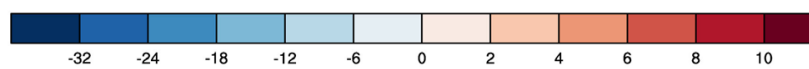

$\overrightarrow{0.025 \mathrm{~kg} /\left(\mathrm{m}^{*} \mathrm{~s}\right)}$

Figure 5. The whole layer water vapor flux [vector, unit: $\mathrm{kg} /(\mathrm{m} \cdot \mathrm{s} \cdot \mathrm{hPa})]$ and SHA [shadow, unit: 10] for typical cases in the southern branch trough in the "western type" SBT (a) and the "eastern type" SBT (b).

gradient force, the convergence occurs in the negative barotropic region. High level divergence, low level convergence, there must be upward movement; After the SBT, there is negative VA, the anticyclonic vorticity increases, and convergence occurs under the action of geostrophic deflection force, thus making the ground pressurized. Under the action of the pressure gradient force, divergence appears in the barotropic region. High level convergence low level divergence, must sink movement. The positive VA in front of the SBT and the negative VA behind the SBT made the ridge of the upper trough move forward, the surface cyclones and anticyclones strengthened and developed, and the SBT developed from west to east. This may be one of the reasons for the occurrence of several high-value frequency centers from west to east in January of the SBT. Meanwhile, the high-value area of positive VA was consistent with the location of high-value frequency. The VA of the south branch of the eastern type is obviously weaker than that of the western type. 


\subsection{Specific Humidity Advection and Water Vapor Flux}

Specific humidity advection (SHA) is one of the important factors affecting the change of water vapor. SHA $>(<) 0$ causes the increase (decrease) of local specific humidity. From the perspective of SHA distribution, there is no obvious SHA in the activity range of the western type SBT, and the negative value center of the eastern type SHA appears near Bay of Bengal where the southern branch trough concentrates, and the water vapor flux of the whole layer also changes greatly here.

It can be seen from the distribution of water vapor flux in the whole layer that the daily water vapor transport in the south branch of the western type is obviously different from that in the eastern type. According to the numerical analysis of water vapor flux, there is no positive or negative SHA center near the south branch of the eastern type, while there is negative SHA center near the south branch of the western type.

Therefore, the formation of the SBT in January is closely related to VA, and the formation of the SBT in May is closely related to SHA and water vapor flux, that is, the dynamic effect has a greater impact in January, while the water vapor effect has a greater impact in May.

\subsection{T-N Wave Flux}

T-N wave flux has a good effect in describing atmospheric long-wave perturbations with large amplitude zonal non-uniform airflow. Since the calculation of T-N wave flux firstly relies on a climatic background field to calculate the disturbance, in this paper, the mean winter background field and spring background field of $41 \mathrm{a}$ of the eastern type SBT were used to calculate the disturbance. As can be seen from Figure 6, when the SBT occurs (purple square), abnormal signals appear in both the eastward and westward positions. It shows that the generation of the south branch channel has a certain relationship with the T-N wave flux, accompanied by abnormal energy signals.

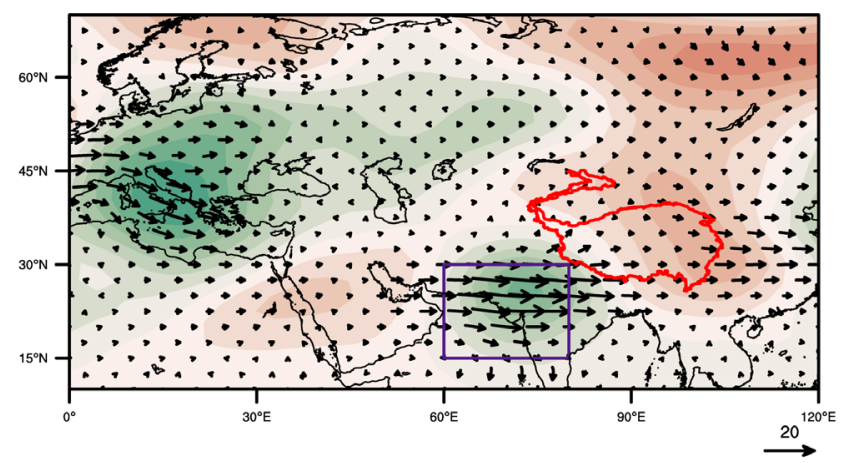

(a)

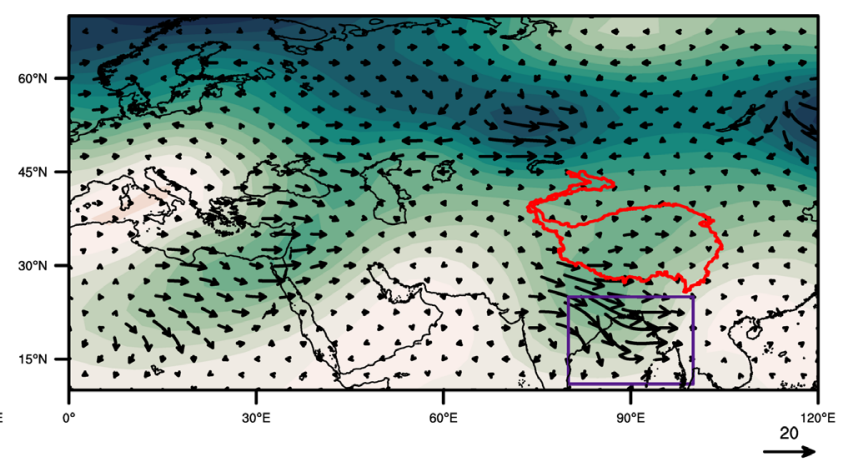

(b)

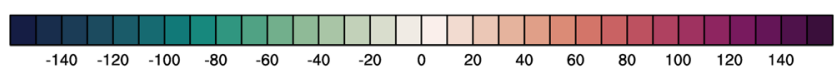

Figure 6. The mean $500 \mathrm{hPa}$ T-N wave activity flux (vectors, units: $\mathrm{m}^{2} \cdot \mathrm{s}^{-2}$ ) and geopotential height anomaly (shading, Units: gpm). 


\section{Summary and Discussion}

The full vorticity equation was used to diagnose the contribution of various factors, and the differences in dynamics, thermodynamics and energy of the SBT at different locations were further explored, and the following conclusions were drawn:

1) The location of the SBT is more eastward in winter, and more westward in spring.

2) The southern branch of the "eastern type" has more obvious vorticity advection than the southern branch of the "western type", and the dynamic action is stronger; the "western type" south branch has stronger $Q_{1}$, specific humidity advection and water vapor flux than the "eastern type" south branch, which is greatly affected by thermal action and water vapor.

3) When the "east type" SBT and the "west type" SBT occur, the T-N wave flux appears obvious abnormal energy fluctuation propagation.

In this paper, based on the diagnostic analysis of the SBT by typical example, using the synoptic diagnosis and statistical method of combining the climatology, the dynamics, thermodynamics and energy characteristics of the south branch trough at two key locations are compared and analyzed, not only comparing only $500 \mathrm{hPa}$, but also not comparing the formation process from the moment of formation to the moment of death in each of the SBT examples. At present, the contribution of VA and SHA has not been quantified at the time of the emergence of the SBT, and the formation mechanism of the SBT has not been definitively which still needs further study.

\section{Acknowledgements}

I would like to extend my deep gratitude to all those who have offered me practical, cordial and selfless support in writing this thesis and the men and women who took part in the study.

Firstly, I am extremely grateful to my supervisor, Prof. Zhou Shunwu. He guides me, influences me and helps me in the process of writing this thesis. It is with his patience, generosity, and encouragement that I finally write, revise and perfect my thesis. He is a distinguished professor who gives me the opportunity to walk into the academic world. To study with them will always be an honor for me and his instructions will follow me in my future studies.

Then, I would like to thank my classmates, senior brothers and senior sisters, who have provided me with a lot of selfless help, which has made my academic and life more convenient and enjoyable.

Ultimately, I also want to thank my parents. It is their understanding and patience that make this thesis possible.

\section{Conflicts of Interest}

The authors declare no conflicts of interest regarding the publication of this 
paper.

\section{References}

Adler, R. F., Saviano, M., Huffman, G. J. et al. (2018). The Global Precipitation Climatology Project (GPCP) Monthly Analysis (New Version 2.3) and a Review of 2017 Global Precipitation. Atmosphere, 9, 138. https://doi.org/10.3390/atmos9040138

Bolin, B. (1950). On the Influence of the Earth's Orography on the General Character of the Westerlies. Tellus, 2, 184-195. https://doi.org/10.3402/tellusa.v2i3.8547

Chaudhury, A. M. (1950). On the Vertical Distribution of Wind and Temperature over Indo-Pakistan along the Meridian $76^{\circ} \mathrm{E}$ in Winter. Tellus, 2, 56-62.

https://doi.org/10.3402/tellusa.v2i1.8525

Chen, Y., Ding, Y. H., Xiao, Z. N. et al. (2006). The Impact of Water Vapor Transport on the Summer Monsoon Onset and Abnormal Rainfall over Yunnan Province in May. Chinese Journal of Atmospheric Sciences, 30, 25-37. (In Chinese)

He, J. H., Qi, L., Wei, J. et al. (2007). Reinvestigations on the East Asian Subtropical Monsoon and Tropical Monsoon. Chinese Journal of Atmospheric Sciences, 31, 1257-1265. (In Chinese)

Herrera, R. G., David, G. P., Emiliano, H. M. et al. (2001). Influence of the North Atlantic Oscillation on the Canary Islands Precipitation. Journal of Climate, 14, 3889-3903. https://doi.org/10.1175/1520-0442(2001)014<3889:IOTNAO >2.0.CO;2

Li, X. Z., \& Wen, Z. (2016). Modulation of the Interannual Variation of the India-Burma Trough on the Winter Moisture Supply over Southwest China. Climate Dynamics, 46, 147-158. https://doi.org/10.1007/s00382-015-2575-4

Lin, Z. Q. (2015). Objective Identify Method and Climatic Characteristics of Southern Branch Trough. Plateau Meteorology, 34, 684-689. (In Chinese)

Lin, Z. Q. (2016). Influence of the Southern Branch Trough on Plateau of Southwestern China Daily Precipitation in Wintertime. Plateau Meteorology, 35, 1456-1463. (In Chinese)

Qin, J., Ju, J. H., Xie, M. E. et al. (1997). Weather Climate over Low Latitude Plateau (pp. 70-73). Beijing: China Meteorological Press. (In Chinese)

Suo, M. Q. (2008). Formation, Propagation and Evolution Characteristics of Wintertime Southern Branch Trough in the Subtropical Westerlies and Its Impacts on the Weather and Climate in China. Ph.D. Thesis, Beijing: Chinese Academy of Meteorological Sciences. (In Chinese)

Suo, M. Q., \& Ding, Y. H. (2009). The Structures and Evolutions of the Wintertime Southern Branch Trough in the Subtropical Westerlies. Chinese Journal of Atmospheric Sciences, 33, 425-442. (In Chinese)

Tao, S. H. (1953). The Influence of the Trough from Indo-Burma on the Weather of Southern China in Winter. Acta Meteorologica Sinica, 23, 172-192. (In Chinese)

Wang, L. J., Wen, M., Luo, L. et al. (2005). The Relationship between the Position Variation of the West Pacific Subtropical High and the Apparent Heating. Journal of Tropical Meteorology, 21, 488-496. (In Chinese)

Wu, G. X. (2004). Recent Progress in the Study of the Qinghai-Xizang Plateau Climate Dynamics in China. Quaternary Sciences, 24, 1-9. (In Chinese)

Wu, G. X., \& Liu, H. Z. (1999). Complete Form of Vertical Vorticity Tendency Equation and Slantwise Vorticity Development. Acta Meteorologica Sinica, 57, 1-15. (In Chinese)

Wu, G. X., Guan, Y., Wang, T. M. et al. (2010). Vortex Genesis over the Bay of Bengal in 
Spring and Its Role in the Onset of the Asian Summer Monsoon. Science China Earth Sciences, 40, 1459-1467. (In Chinese)

Ye, D. Z., \& Gao, Y. X. (1979). Meteorology of the Qinghai-Xizang Plateau (pp. 1-278). Beijing: Science Press. (In Chinese)

Yeh, T. C. (1950). The Circulation of the High Troposphere over China in the Winter of 1945-46. Tellus, 2, 173-183. https://doi.org/10.1111/j.2153-3490.1950.tb00329.x

Yin, M. T. (1949). A Synoptic-Aerologic Study of the Onset of the Summer Monsoon over India and Burma. Journal of Atmospheric Sciences, 6, 393-400.

Zhang, L., Rong, Y. S., Wei, J., et al. (2017). Relationship between Wintertime Southern Branch Trough and Runoff of Wujiang Basin in Flood Period. Journal of the Meteorological Sciences, 37, 766-775. 